\title{
Uzun çalışma saatlerinin insanî gelişmişlik endeks değeri üzerindeki etkisi
}

\section{The effect of long work hours on human development}

\author{
Murat Dinçer ${ }^{1}$ \\ Seda Bağdatlı Kalkan²
}

\begin{abstract}
1 Arş. Gör., İstanbul 29 Mayıs Üniversitesi İktisadi ve İdari Bilimler Fakültesi Sosyal Hizmet Bölümü, İstanbul, Türkiye

İstanbul Ticaret Üniversitesi Fen Bilimleri Enstitüsü İstatistik Tezli Yüksek Lisans Programı Öğrencisi, İstanbul, Türkiye mdincer@29mayis.edu.tr

ORCID: 0000-0001-7276-8738

2 Doç. Dr., İstanbul Ticaret Üniversitesi İnsan ve Toplum Bilimleri Fakültesi İstatistik Bölümü, İstanbul, Türkiye, sbagdatli@ticaret.edu.tr
\end{abstract}

ORCID: 0000-0003-3002-2983

\section{Sorumlu Yazar/Corresponding Author:}

Seda Bağdatli Kalkan,

İstanbul Ticaret Üniversitesi İnsan ve Toplum Bilimleri Fakültesi İstatistik Bölümü, İstanbul, Türkiye, sbagdatli@ticaret.edu.tr

Başvuru/Submitted: 12/01/2021

1. Revizyon/Revised: 14/02/2021

2. Revizyon/Revised: 20/02/2021

Kabul/Accepted: 27/02/2021

Yayın/Online Published: 25/03/2021

Atıf/Citation: Dinçer, M., \& Bağdatlı Kalkan, S., Uzun çalışma saatlerinin insanî gelişmişlik endeks değeri üzerindeki etkisi, bmij (2021) 9 (1): 186-199, doi: https://doi.org/10.15295/bmij.v9i1.1746

\section{Öz}

Ülkelerin gelişmişlik düzeyleri tarihten bugüne kadar farklı biçimlerde ele alınmış ve özellikle Sanayi Devrimi'nden sonra ülkelerin gelişmişlikleri gayrisafi yurt içi hasıla miktarları ile ölçülmeye çalışılmıştır. Bu durum özellikle II. Dünya Savaşı sonrasında gelişen insan hakları anlayışı ile çokça eleştirilmiş ve ilk kez 1990 yılında Birleşmiş Milletler tarafından İnsanî Gelişme Raporu yayınlanmıştır. Bu raporda yer alan İnsanî Gelişmişlik Endeksi hesaplamaları her ne kadar pek çok farklı açıdan eleştirilmiş olsa da yeni bir kalkınma ve gelişmişlik anlayışına dayanması temelinde önemli kabul edilmiştir. Bu endeks ile gerçekleştirilen hesaplamalardan yola çıkarak insanî gelişmişliğin pek çok farklı unsur ile ilişkisi incelenmiştir. Bu çalışmada da insanî gelişmişlik ve çalışma saatleri ilişkisi Genelleştirilmiş Tahmin Denklemleri yöntemi ile incelenmeye çalışılmıştır. Çalışmada Ekonomik Kalkınma ve İş birliği Örgütüne üye 35 ülkenin 2010-2017 yılları arasındaki verileri kullanılmıştır. Çalışmanın sonucunda çalıșma saatleri ve insanî gelişmişlik endeksi bileşenleri arasında ters yönlü bir ilişkinin varlığı tespit edilmiştir. Bu bulgular mevcut iş ve çalışma anlayışını tartışmalı hale getirmektedir. Bu noktada bireysel ve toplumsal yaşamda verimlilik odaklı yeni bir paradigmaya ihtiyaç duyulduğu açıktır.

Anahtar Kelimeler: İnsanî Gelişme, Çalışma Saatleri, Genelleştirilmiş Tahmin Denklemleri

Jel Kodlari: I31, J81

\begin{abstract}
The countries' development levels have been handled differently until today, especially after the Industrial Revolution; the countries' development has been tried to be measured by the gross domestic product amounts. This is especially true of II. It has been criticized a lot with the understanding of human rights that developed after World War II, and the Human Development Report was published for the first time in 1990 by the United Nations. Although the Human Development Index calculations included in this report have been criticized in many different ways, they have been deemed necessary on the basis that they are based on a new understanding of development and development. Based on the calculations made with this index, the relationship of human development with many different factors has been examined. In this study, the relationship between human development and working hours has been analyzed using the Generalized Estimation Equations method. In the study, the data of 35 countries that are members of the Organisation for Economic Co-operation and Development between 2010-2017 were used. As a result of the study, an inverse relationship between working hours and human development index components was determined. These findings make the current understanding of work controversial. At this point, it is clear that a new productivity-oriented paradigm is needed in individual and social life.
\end{abstract}

Keywords: Human Development, Work Hours, Generalized Estimate Equation

Jel Codes: 131 , J81 


\section{Extended Abstract}

\section{The effect of long work hours on human development}

\section{Literature}

Human Development Index is a value whose relationship with many different factors has been examined since its first publication in 1990. The index, which emerged with the changing understanding of human rights, especially after the 1950s, is criticized from different angles, but it remains an important indicator. With this importance, many different studies have examined countries' human development levels in terms of their relationship with various factors. The said studies have revealed a positive relationship between human development and various factors such as success and stability in financial markets, PISA test results, economic development, and scientists' invention performance. In terms of the relationship with working hours, it was concluded that human development negatively correlates with working hours in a study conducted in Brazil with the data for the years 2008-2012. Besides, various studies of long working hours have shown that it slows down the integration of immigrants into society, has negative effects on family relations, and decreases productivity.

\section{Design and method}

Within the study's scope, the relationship between working hours and human development has been tried to be revealed. On this basis, the data of the member countries of the Organisation for Economic Cooperation and Development Organization were used. In the study where data for the years 2010-2017 were collected, the data of 35 countries in total were included in the analysis. The data used in the study were obtained from the electronic databases of the Organisation for Economic Cooperation and Development Organization and the United Nations Development Program. There is no missing observation in the data set used. The data set variables can be explained as; 'wh' average annual working hours, 'hdi' Human Development Index values of countries, 'sch' average years of education, 'lexp' average life expectancy and 'gni' average national income per capita. Since a longitudinal data set is preferred, the study's method was determined as Generalized Estimation Equations. The R Studio program and the geepack command were used in the analysis of the study. A total of 16 different models were established, with four different employee correlation structures. The QIC criterion, which is the goodness of fit criterion, was used in comparing the models.

\section{Findings and discussion}

Within our study's scope, a statistically significant relationship could not be established between working hours and the Human Development Index value. However, it has been concluded that there is a statistically significant relationship between the Human Development Index parameters, which are average years of education, average life expectancy, average national income per capita, and working hours. One unit increase in working hours according to working results; creates an effect of average education year (-0.00277), average life expectancy (-0.00408) and per capita income (-41.79). This shows that working hours are related to human development and that the increase in working hours negatively affects human development. Based on its results, our study presented similar results with other studies in the literature. This result coincides with research outputs such as; working hours are negatively related to human development value, the decrease in the integration of immigrants who work long hours into society, long work damages family relations, and increase in working hours decreases productivity.

\section{Conclusion, recommendation and limitations}

Within the scope of our study, it has been revealed that working hours have a negative relationship with human development. The comments to be made on this issue should be constructed by taking into account the influence of different sectors and working styles and the dominant working cultures in societies, and this can be considered a limitation of the study. However, the results obtained within our study's scope are considered quite critical and explanatory in this regard. This situation adds meaning to reducing working hours and days in various European countries, especially Finland. Nowadays, it is clear that a new business and working understanding needs to be developed, especially considering the technological opportunities and the mobility of transformation into a digital society. 


\section{Giriş}

İnsanî gelişmişlik, toplumların ve bu toplumlar içerisindeki bireylerin sosyoekonomik gelişmişliklerine karşılık gelen bir kavramdır. Yaşamda karşılık bulduğu hususlar açısından değerlendirildiğinde insanî gelişmişliğin ölçülmesi, insanî açıdan gerekli ilerlemenin sağlanabilmesi açısından oldukça önemlidir. Burada her ne kadar barındırdığı felsefi boyutu ile insanî gelişmişliğin tam olarak ölçülebilmesi zor olsa da nicel bazı ölçütler kullanarak en azından çeşitli yorumlamalar gerçekleştirmek mümkündür. Günümüzde bu ölçütlerin en yaygın olanlarından bir tanesi şüphesiz İnsanî Gelişmişlik Endeksidir (İGE).

1990 yılından bu yana hesaplanan İGE, toplumların Dünya içerisinde insanî gelişmişlik açısından yer aldığ1 konumu ve önceki yıllara göre insanî gelişmişlik düzeyindeki değişimini göstermektedir. Bu yönüyle toplumların ve devlet mekanizmalarının sosyo-ekonomik gelişmişliklerine ilişkin bir karnesi niteliğinde olan İGE hem tek başına hem de diğer faktörlerle ilişkisi bakımından çeşitli çalışmalarda çokça kullanılmaktadır.

Nitekim ulusal ve uluslararası literatürde çeşitli ekonomik ve sosyal faktörlerle İGE arasındaki ilişkinin saptanmasına yönelik çalışmalar mevcuttur. İGE'nin yaşamdaki fenomenlerle olan bağ1 düşünüldüğünde bu çalışmalar, hem çeşitli faktörlerin insanî gelişmişlik üzerindeki etkisinin anlaşılabilmesi hem de toplumların insanî gelişmişliklerini arttırmaları açısından oldukça önemli ve gereklidir.

Bu gereklilikten yola çıkarak çalışma, çalışma saatleri ve insanî gelişmişlik düzeyi arasındaki ilişkinin ölçülmesi amacı ile gerçekleştirilmektedir. Bu temelde çalışma, dünyanın hemen her yerindeki insanların yaşamının büyük çoğunluğunda önemli bir yeri bulunan çalışma aktivitesinin insanî gelişmişlik üzerindeki etkisini istatistiksel açıdan kanıtlanabilir bir teknik ile incelenmesi açısından önemli kabul edilmektedir.

Çalışmada öncelikli olarak İnsanî Gelişmişlik Endeksi incelenecek ve çalışmanın yöntemi ile kullanılacak veri seti açıklanacaktır. Bunun ardından çalışmada kullanılan veri setinde yer alan ülkelere ilişkin gözlemler üzerinden Genelleştirilmiş Tahmin Denklemleri (GTD) uygulanacak ve çıtıları yorumlanacaktır.

\section{İnsanî gelişmişlik endeksi}

Dünya tarihinde gelişme ve gelişmişlik kavramlarına yönelik tanımların geliştirilmesinde konjonktürel koşullar ve anlayış biçimleri oldukça önemli olmuştur. Özellikle Sanayi Devrimi ile birlikte gelişmişlik; makineleşme, artı değer üretim miktarı ve bunun sonucunda sermaye birikimi olarak anlaşılmaya başlanmıştır. Bu durum, oldukça farklı insan hakkı ihlallerine neden olmuştur. Nitekim bu gelişmişlik anlayışı daha fazla zenginliğe sahip olmak için bedeli ne olursa olsun daha fazla artı değer elde etmek üzerine kuruludur.

Bu anlayış çeşitli eleştirilere maruz kalmış ve zaman içerisinde değişim kaçınılmaz olmuştur. Özellikle kentleşme ile birlikte başlayan işçi hareketleri, profesyonelleşen sosyal hizmet aktiviteleri ile artan savunuculuk faaliyetleri ve çeşitli protest hareketlerin etkisi ile gelişen insan hakları anlayışı ile hâkim gelişmişlik anlayışı yavaş yavaş değişim göstermeye başlamıştır (Yiğit, 2020). Burada özellikle var olan zenginliğin (genellikle gayri safi yurt içi hasıla) tek başına bir gelişmişlik göstergesi olamayacağ yönündeki eleştiriler ve her insanın sırf insan olmaktan ileri gelen hakları bulunduğu anlayışının yaygınlaşması ile gelişimin toplumun tüm kesimlerinin birlikte kalkınması ile mümkün olabileceği anlayışı doğmuştur. Tam da bu noktada ulusal ve uluslararası düzeyde insanî gelişmişliğin çeşitli temel parametreler üzerinden ölçülmesi tartışılmaya başlanmıştır.

Bu tartışmalar, ilgili ölçümlerin gerekliliği ve buna ilişkin önerilen yöntemler bağlamında başta ekonomistler ve bunlara ek olarak çeşitli alanlardan sosyal bilimciler tarafından gerçekleştirilen çalışmalarla 20. Yüzyılın sonlarında oldukça yaygınlaşmışıı. Bu sürecin bir çıktısı olarak 1990 yılında ekonomist Mahbub-ul Haq'ın geliştirdiği insanî gelişme yaklaşımından yararlanılarak İnsanî Gelişme Raporu hazırlanmıştır. İGE hesaplamalarını içeren bu çalışmanın felsefi altyapısı Amartya Sen'in 'Yapabilirlik Yaklaşımı' adı verilen yaklaşıma dayanmaktadır. Bu bağlamda İGE; gelişmiş̧liğin ölçülmesinde, sadece ekonomik ölçütlerin esas alındığı yaklaşımlar yerine insanların kabiliyetleri doğrultusunda sahip oldukları fırsatlar ve seçim haklarının da gelişmişlik ile ilişkilendirildiği alternatif bir yaklaşımdır. İGE yaklaşımında insanî gelişme, insanların seçme özgürlüklerinin arttırılmasıdır (Meydan ve Sarı, 2018). Bu temelde ilgili çalışmada insanlara, fırsatlara ve seçimlere vurgu yapılması söz konusudur. 
Geliştirilen bu yeni yaklaşıma göre gelir artışı bir amaç değil araçtır. Daha açık bir ifadeyle büyüyen gayri safi yurt içi hasılanın insanî gelişmeye ve bununla ilgili parametrelere ilişkin yatırımlara harcanması esastır. Burada ayrıca, yalnızca bireysel gelişmenin yeterli olmayacağı aynı zamanda devletlerin yaşamda gerekli fırsatların sunulması ile ilgili mekanizmaları hayata geçirmesi gerekliliğine de vurgu yapılmaktadır. Örneğin bir toplumda çocukların nitelikli eğitime erişimi önemlidir ancak bu eğitimi alanların ileriki yıllarda iş yaşamına katılması ve bu eğitimlerini toplumsal fayda sağlayacak şekilde uygulamaya geçirebilmesi için de fırsatlara sahip olması gereklidir. Burada sunulan fırsatların değerlendirilmesi konusunda bireyler özgür kabul edilmelidir. Nitekim her birey yaşamdaki fırsatları ile ilgili seçme özgürlüğüne sahip olmalı, hiçbir yapı onun yerine karar vermemelidir.

Bu temel ilkeler insanî gelişmişlik ile ilgili ölçümlerin kapsamının belirlenmesi açısından önemlidir. Bu ilkelerden yola çıkarak insanî gelişmişliğin ölçülmesi için günümüzde kullanılan parametreler; iyi bir yaşam standardı, sağlıklı ve uzun yaşam ile bilgiye erişim şeklindedir. Şekil 1'de insanî gelişmişliğin hesaplanmasında kullanılan parametreler ve buna bağlı alt parametreler gösterilmektedir.

Şekil 1'de görülebileceği üzere iyi yaşam standardı kişi başına düşen gayri safi yurt içi hasıla miktarı ile ilişkilidir. Uzun ve sağlıklı yaşam ise doğumda beklenen yaşam süresi veya bir diğer değişle ortalama yaşam süresi ile ölçülmektedir. Bilgiye erişim ise ortalama okullaşma yılı ve beklenen okullaşma yılı ile ilişkilidir

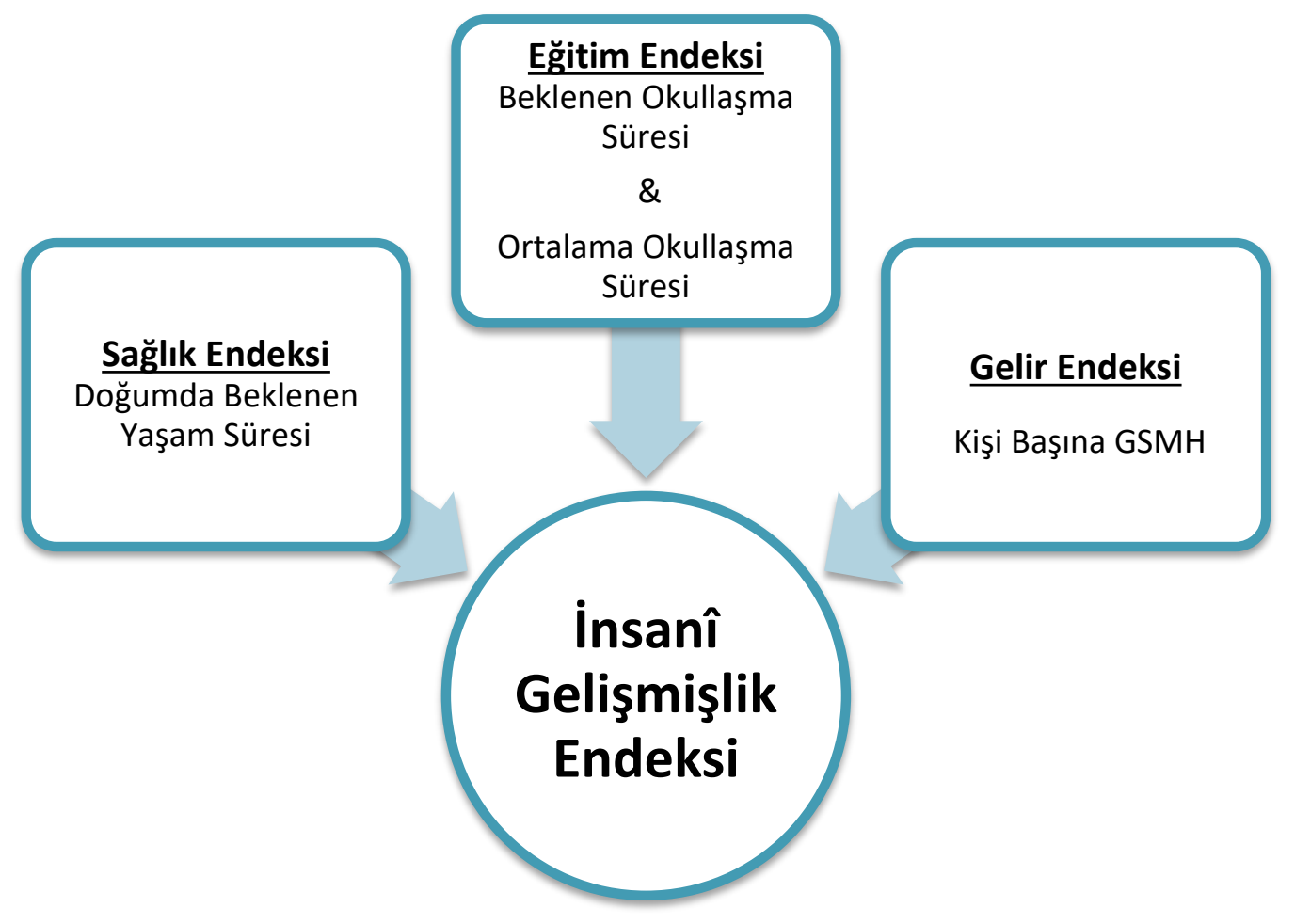

Şekil 1. İnsanî Gelişmişlik Endeksi Parametreleri

Kaynak: (T.C. Kalkınma Bakanlığı Sosyal Sektörler ve Koordinasypn Genel Müdürlüğü, 2011)

Bu parametreler üzerinden her bir ülke için ilgili boyutlara ilişkin bir değer hesaplanmakta ve bu değerlerin ilişkisi üzerinden toplam bir İGE değeri ortaya çıkartılmaktadır. Bu hesaplamalara ilişkin formülasyon aşağıdaki gibidir; (UNDP, 2019)

\section{Boyut Endeksi Hesaplama;}

$$
\text { Boyut Endeksi }(0-1)=\frac{\text { Gerçek Değer }- \text { Minimum Dĕger }}{\text { Maksimum Değer - Minimum Değer }}
$$

İGE Hesaplama;

$$
\dot{\mathrm{IGE}}=\left(I_{\text {Sağllk }} \times I_{\text {Ĕ̆itim }} \times I_{\text {Gelir }}\right)^{1 / 3}
$$


İGE hesaplamasında beklenen eğitim süresi ve ortalama eğitim süresi olmak üzere 2 ayrı değişkenden oluşan eğitim endeksi, yukarıda açıklanan boyu endeksi hesaplama formülasyonu üzerinden bu iki alt değişken için hesaplanan değerlerin aritmetik ortalamasıdır. Gelir endeksi ise değerlerin doğal logaritması alınarak hesaplanır (UNDP, 2019).

Tablo 1, İnsanî Gelişmişlik Endeksi bileşenlerine ait en yüksek ve en düşük değerleri göstermektedir.

Tablo 1. İnsanî Gelişmişlik Endeks Bileşenlerinin En Yüksek ve En Düşük Değerleri

\begin{tabular}{|c|c|c|c|}
\hline$\underset{*}{*}$ & Gösterge & En Düşük Değer & En Yüksek Değer \\
\hline \multirow{2}{*}{ 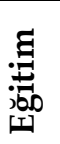 } & Ortalama Eğitim Yılı & 0 & 15 \\
\hline & Beklenen Eğitim Yılı & 0 & 18 \\
\hline ஸ̆ & Doğumda Beklenen Yaşam Süresi & 20 & 85 \\
\hline ن̈ & $\begin{array}{c}\text { Kişi Başına Düşen Gayri Safi Yurt İçi } \\
\text { Hasıla (\$) }\end{array}$ & 100 & 75.000 \\
\hline
\end{tabular}

Kaynak: (UNDP, 2019)

Günümüzde İGE değeri; 0.550 'den küçük olan ülkeler düşük insanî gelişme, 0.550 ile 0.699 arasında olan ülkeler orta insanî gelişme, 0.700 ile 0.799 arasında olan ülkeler yüksek insanî gelişme ve 0.800 ile 1 arasında olan ülkeler ise çok yüksek insanî gelişme kategorisinde değerlendirilmektedir (UNDP, 2018).

İnsanî Gelişmişlik Endeksi, her ne kadar soyut bir olgu olan gelişmişliğin somut bazı parametreler üzerinden ölçülmesine olanak tanımış olması itibari ile oldukça önemli bir konumda olsa da ortaya çıktığı günden bugüne kadar çeşitli eleştirilerin odağında olmuştur. Bu eleştirilerden başlıcaları, İGE hesaplamalarında; sağlık, eğitim ve gelir ile ilgili gösterge değerlerinin toplumdaki yayılımı dikkate alınmadan bir bütün olarak değerlendirilmesi, gelir dağılımı adaletsizliğine ilişkin unsurların hesaplamaya dahil edilmemesi, toplumsal cinsiyet eşitsizliğine ilişkin faktörlerin dikkate alınmaması şeklindedir. Ayrıca politik özgürlük, insanî özgürlük ve mutluluk gibi faktörlerin endeks hesaplamasında bulunmaması da diğer eleştirilerdendir (UNDP, 2018). Burada yaşam kalitesinin yalnızca eğitim ve sağlık üzerinden değerlendirilmesi de tartışma konusu olmuştur. Ek olarak ortalama yaşam süresi, okullaşma yılı vb. gibi ölçütlerin eğitim ve sağlık ile ilgili genel bir yorum geliştirmek için yeterli olamayacağına ilişkin eleştiriler de mevcuttur (Meydan ve Sarı, 2018).

İGE hesaplamalarına ilişkin bir diğer önemli eleştiri de sürdürülebilirlik ile ilgilidir. Nitekim bazı çalışmalar Brezilya ve Endonezya ülkelerindeki İGE parametresindeki artışın kaynağına dikkat çekmiştir. Buna göre ilgili ülkelerde İGE artışı aşırı doğal kaynak tüketimi ile ilişkilendirilmiştir. Bu uygulamalar, doğaya verilen zarar ve sürdürülebilirlik bağlamında değerlendirildiğinde eleştirilere maruz kalmıştır. Bu noktada insanî gelişmeye yönelik hesaplamalara sürdürülebilirlik ile ilgili ölçütlerin eklenmesi gerektiği vurgulanmıştır (Sagar ve Najam, 1998). Ayrıca çeşitli çalışmalar; çalışma şartlarından ekonomik istikrara, çevreden sosyal ilişkilere kadar pek çok farklı etmenin daha İGE ile ilişkili olduğunu göstermiş ve hesaplamada kullanılan parametrelerin arttırılması gerektiğini matematiksel olarak ortaya koymuştur (Rannis, Stewart ve Samman, 2006).

Bu eleştiriler çerçevesinde ilk kez 1990 yılında bir rapor içerisinde yayınlanan İnsanî Gelişmişlik Endeksi ve buna yönelik hesaplamalar günümüze kadar; yoksulluk, toplumsal cinsiyet, insanî özgürlük, politik özgürlük, eşitsizlik vb. hususlara iliş̧in alt endeksler eklenerek geliştirilmiştir (United Nations Development Programme, 2020). Burada her ne kadar çok çeşitli eleştirilerin odağında olsa da yine de günümüzde sürdürülebilir bir kalkınma anlayışının varlığı ve gelişimi açısından oldukça önemli bir konumda olan İnsanî Gelişme Endeksi, uluslararası alanda hala dikkate değer bulunmaktadır (Meydan ve Sarı, 2018). 


\section{İnsanî gelişmişlik ve çalışma süreleri ilişkisi}

İnsanî Gelişmişlik Endeksi, formülasyonu ve gelişmişliğin gerçek boyutunu açıklayabilmesi gibi çeşitli açılardan eleştirilmekte ise de bugün özellikle akademik çalışmalarda önemli bir konumdadır. Nitekim pek çok araştırmacı, alanları ile ilgili konularda gerçekleştirdikleri analizler için endeks değerlerini kullanmaktadır. Bu çalışmalar insanî gelişmişliğin çeşitli faktörlerle olan ilişkisini ortaya koymaktadır. Çalışmanın konusu olan İnsanî Gelişmişlik Endeksi ve çalışma saatleri ilişkisine yönelik çalışmalara ise hem ulusal hem de uluslararası literatürde sıkça rastlanmamaktadır. Bu açıdan çalışmanın, literatüre önemli bir katkı sağlayacağı düşünülmektedir. Ancak çalışma saatlerinin, farklı toplumlarda bireysel ve toplumsal boyutta yarattığı etkiye ilişkin çalışmalar mevcuttur. Bu başlık altında bahsi geçen çalışmaların sonuçları incelenecektir.

Londra' da yaşayan Türkiye ve Kıbrıs kökenli göçmenlere yönelik gerçekleştirilen bir çalışmanın sonucu buradaki göçmenlerin günde 16 saate yaklaşan bir mesai süresinin olduğunu ve bu durumun özellikle İngilizce öğrenmek ve devlet mekanizmaları ile ilişki kurmak gibi faaliyetleri aksatması nedeniyle entegrasyonu yavaşlatıcı etkisinin bulunduğunu ortaya koymuştur (Şeker, ve diğerleri, 2015). Literatürde çalışma saatlerinin aile yaşamı üzerindeki etkisi ile ilgili çalışmalara da rastlamak mümkündür. Yeni Zelanda' da gerçekleştirilen bir araştırma ebeveynlerin uzun çalışma saatleri ile aile hayatı üzerindeki çeşitli olumsuzlukları bağdaştırdığını ve çalışma saatlerinin aile içi dinamikleri zedeleyen etmenlerden biri olarak değerlendirildiğini ortaya koymaktadır (Fursman, 2009). Pakistan'da gerçekleştirilen bir diğer araştırma ise çalışma saatleri ile ilişkili olduğu belirtilen iş stresi ve iş doyumunun aile yaşantısına olumsuz yansıdığını göstermektedir (Akhtar, Kashif, Arif ve Khan, 2012).

Ayrıca Hollanda'daki bir çağrı merkezi çalışanları üzerinde gerçekleştirilen bir çalışmada, çalışma saatleri ile işçilerin üretkenlikleri arasında ters yönlü bir ilişki olduğu ortaya konmuştur (Collowet ve Sauermann, 2019). Çalışma saatlerinin işçi sağllğı üzerine olan etkileri ile ilgili olarak ise Wong ve diğerleri (2012) tarafından yapılan bir çalışmanın sonuçları dikkat çekicidir. Bir meta analiz araştırması olarak gerçekleştirilen bu çalışmada toplam 46 makalenin sonuçları incelenmiştir. Bu inceleme sonucunda uzun çalışma saatlerinin öncelikli olarak meslek hastalığı riskini arttırdığı ve akıl sağlığı ile fiziksel sağlık için de risk teşkil ettiği belirlenmiştir (Wong, Chan ve Ngan, 2012).

Hava kirliliği, çalışma saatleri ve ortalama yaşam süresi ilişkisinin Amerika Birleşik Devletleri'nin eyaletleri özelinde incelendiği bir araştırmanın sonuçları ise bu üç faktörün birbiriyle olan ilişkisine dikkat çekmiştir. Çalışmanın sonuçları, çalışma saatleri ile ortalama yaşam süresi arasında negatif yönlü bir ilişki olduğunu ortaya koymuştur. Benzeri yönlü bir ilişki hava kirliliği ve ortalama yaşam süresi için de tespit edilmiştir. Araştırmacılara göre bu analiz çıktıları, hem hava kirliliği gibi çevresel faktörlerin hem de çalışma süreleri gibi sosyoekonomik faktörlerin ortalama yaşam süresindeki etkisini göstermektedir. Bu temelde insan ömrünü uzatmak ve hastalıkların önüne geçmek adına bütüncül yaklaşımlara ihtiyaç duyulmaktadır (Jorgenson, ve diğerleri, 2020). Çalışma saatleri ile ilişkisi incelenen bir diğer faktör ise kişi başına düşen Gayri Safi Yurt İçi Hasıla (GSYİH) olmuştur. Schein ve Haruvi (2017) tarafından gerçekleştirilen çalışmanın sonuçlarına göre bir ülkede ortalama çalışma saatlerindeki azalma kişi başına düşen GSYİH miktarında azalmaya yol açmamaktadır. Araştırmacılara göre, zengin ülkelerdeki işçilerin görece daha yoksul olan ülkelerdeki iş̧̧ilerden az çalışıyor olması bu yargıyı destekler niteliktedir (Schein ve Haruvi, 2017). Son olarak çalışmanın konusu ile benzerliği bakımından en dikkat çekici araştırma ise Brezilya'da İnsanî Gelişmişlik Endeks değerleri ve çalışma saatleri arasındaki ilişkinin incelendiği çalışma olmuştur. Çalışmada gerçekleştirilen korelasyon analizi çıtıları 2008-2012 yılları arasında iki faktör arasında ters yönlü bir ilişki olduğunu ortaya koymuştur (Klafke, 2017).

\section{Materyal ve metot}

Çalışma kapsamında Ekonomik Kalkınma ve İş birliği Örgütü (Organisation for Economic Co-operation and Development - OECD) üye ülkelerinin verileri kullanılmıştır. Toplamda 37 üyesi bulunan OECD ülkelerinden Türkiye ve Kolombiya'ya ait veriler, kayıp gözlemler barındırmaları nedeniyle çıkartılmışır. Diğer ülkelere ilişkin verilerde kayıp gözlem bulunmamaktadır. Buna göre gerçekleştirilen analizlerde verileri kullanılan ülkeler sırasıyla; Almanya, Amerika Birleşik Devletleri (ABD), Avustralya, Avusturya, Belçika, Birleşik Krallık, Çek Cumhuriyeti, Danimarka, Estonya, Finlandiya, Fransa, Hırvatistan, Hollanda, İrlanda, İspanya, İsrail, İsveç, İsviçre, İtalya, İzlanda, Japonya, Kanada, Kore Cumhuriyeti, Letonya, Litvanya, Lüksemburg, Meksika, Norveç, Polonya, Portekiz, Şili, Slovakya, Slovenya, Yeni Zelanda ve Yunanistan şeklindedir. Burada verileri kullanılan ülkelerinin çoğunlukla Avrupa kıtasında bulunduğu buna ek olarak Kuzey ve Latin Amerika ile bazı Okyanusya ülkelerinin de çalışmaya dahil edildiği görülmektedir. 
Gerçekleştirilen analizler için kullanılan veri seti içerisinde yer alan değişkenlere ilişkin açıklamalar Tablo 2'de sunulmuştur.

Tablo 2. Veri Seti İçerisinde Yer Alan Değişkenlere İlişkin Açıklamalar

\begin{tabular}{ccc}
\hline Değişken & Açılama & Kaynak \\
\hline wh & İşçi başına yıllık ortalama çalışma saati & (OECD) \\
hdi & İnsanî Gelişmişlik Endeks değeri & (UNDP) \\
sch & Kişi başına ortalama eğitim yılı & (UNDP) \\
lexp & Beklenen ortalama yaşam süresi (yıl) & (UNDP) \\
gni & Kişi başına düşen milli hasıla & (UNDP)
\end{tabular}

Çalışma kapsamında kullanılan veriler çalışma saatleri, İGE değeri ve İGE bileşenlerine ilişkin değerler şeklindedir. 2010-2017 yıllarına ait bu verilere OECD ve Birleşmiş Milletler Kalkınma Programı (United Nations Development Programme - UNDP) veri tabanlarından 5 Aralık 2020 tarihinde ulaşılmıştır. Burada İnsanî Gelişmişlik Endeks bileşenlerinden olan eğitim endeksi için kişi başına ortalama eğitim yılına ilişkin veriler analize dahil edilmiş, beklenen ortalama eğitim yılı değişkeni ise analize dahil edilmemiştir. Bunun nedeni, diğer alt endeks değerlerinin mevcut durumu yansitan göstergeler üzerinden elde edilmiş olmasıdır. Buna uygun olarak çalışmada, eğitim endeksi için de mevcut durumu yansıtan ortalama eğitim yılı değerleri kullanılmıştır.

Çalışma kapsamında Genelleştirilmiş Tahmin Denklemleri Analizinin gerçekleştirilmesi için $R$ Studio programı kullanılmıştır. Program içerisinde analizler geepack komutu ile gerçekleştirilmiş ve korelasyon matrislerinin elde edilmesinde gee komutu çıtılarından yararlanılmıştır. Kullanılan veri seti OECD üyesi 35 ülkenin verilerinden oluşan bir boylamsal veri setidir.

\section{Genelleştirilmiş tahmin denklemleri}

Boylamsal veriler günümüzde sosyal bilimler, psikoloji, ekonomi, sağlık vb. gibi pek çok farklı alanda kullanılan veri yapılardır. Boylamsal verilerde $\mathrm{N}$ birim üzerinden $\mathrm{m}$ farklı zaman diliminde bir bağımlı değişkene ilişkin ölçümler yapılması söz konusudur. Buradan anlaşılabileceği üzere boylamsal verilerde farklı birimlere ilişkin ölçümler belirli bir zaman dilimi aralığında gerçekleştirilir. Ancak boylamsal verilerde gözlemlerin eşit aralıklı alınması şartı bulunmamaktadır (Kılıç ve Çilingirtürk, 2012).

Günümüzde hem ekonometride hem de istatistikte oldukça yaygın bir şekilde kullanılan boylamsal verilerin analizi için farklı yöntemler bulunmaktadır. Bu yöntemler genel itibari ile Karma Etki Modelleri, Koşullu Modeller ve en yaygın olarak kullanılan Marjinal Modeller olarak adlandırılmaktadır. Bu yaklaşımlar Genelleştirilmiş Doğrusal Modellere (GDM) dayanmaktadır. GDM'de bağımlı ve bağımsız değişkenler arasındaki ilişkiyi olabilirlik temelinde açıklamak için kullanılabilen bir teorik çerçeve sunar. Burada bağımlı değişkenin; normal, binom, poisson gibi bir üstel aileye sahip olması durumunda GDM çerçevesi kolayca sonuç verebilir (Çalışkan, 2013).

GDM, bünyesinde yer alan ve en çok kullanılan yöntem olarak tanımlanabilen Marjinal Modeller ise olabilirlik açısından daha geniş bir çerçevede uygulanabilmektedir. Örneğin Marjinal Modellerin içerisinde yer alan ve çalışmanın yöntemi olarak belirlenen Genelleştirilmiş Tahmin Denklemleri (GTD) diğer Marjinal Modellerden farklı olarak yarı-olabilirlik temelinde uygulanmaktadır. Bir başka ifade ile bağımlı değişkenin ortalaması bağımsız değişkenin parametrik bir fonksiyonu olarak kabul edilmektedir (Kılıç ve Çilingirtürk, 2012). İlk olarak 1986 yılında Liang ve Zeger tarafından uygulanan GTD, boylamsal veri analizinde oldukça etkin ve yansız sonuçlar üretebildiği için sıkça tercih edilmektedir (Halekoh, Hojsgaard ve Yan, 2006). Bu yöntemde varyansların homojenlik göstermesi gerekmemektedir ve hata terimleri arasında bir ilişki olması sorun teşkil etmemektedir (Usta ve Çilingirtürk, 2018).

GTD' de ilk olarak birimlerden alınan tahminlerin birbirinden bağımsız olduğu varsayılarak B $^{0}$ Eşitlik $1^{\prime}$ de gösterildiği gibi tahmin edilir. Burada $\mathbf{D}_{\mathbf{i}}, \mathrm{m}_{\mathrm{i}} \times \mathrm{xp}$ boyutlu bir matris, $\mathbf{V}_{\mathbf{i}}$ ise varyans-kovaryans matrisidir.

$$
\mathbf{S}(\mathbf{B})=\sum \mathbf{D}^{\mathrm{T}_{\mathrm{i}}} \mathbf{V}^{-\mathbf{1}_{\mathbf{i}}}\left(\mathbf{y}_{\mathbf{i}}-\boldsymbol{\mu}_{\mathbf{i}}\right)(1)
$$

B'nın hesaplanması ile bu hesaplamada oluşan Pearson kalıntılarının elde edilmesi gerekmektedir. 
$\mathbf{e}_{\mathrm{ij}}=\left(\mathrm{Y}_{\mathrm{ij}}-\mu_{\mathrm{ij}}\right) / \bigvee_{\mathbf{v}}\left(\mu_{\mathrm{ij}}\right)$

$\mathrm{Bu}$ işlemi takiben $\mathbf{V}_{\mathbf{i}}^{\prime}$ nin çalışan korelasyon yapısı tahmin edilir. Ardından $\mathbf{t}$ kadar iterasyon ile $\mathbf{B}$ tahminleri güncellenir ve $\boldsymbol{B}$ parametreleri belirli bir değere yakınsandığında tahminler elde edilmiş olur (Kılıç ve Çilingirtürk, 2012).

GTD'de en önemli hususlardan biri çalışan korelasyon yapısının (R(a)) tahminidir. Korelasyon yapısı, parametre tahminlerine doğrudan etki ettiği için bu yapıların doğru belirlenmesi oldukça önemlidir. Çalışan korelasyon yapılarının doğru belirlenebilmesi için veri seti yeterince anlaşılmalıdır. Literatürde en sık kullanılan çalışan korelasyon yapıları; bağımsız, değiştirilebilir, yapılandırılmamış ve AR-1 olarak sıralanabilir (Yonar ve İyit, 2018).

Bağımsız (independence) çalışan korelasyon yapısı, aynı birimden alınan ölçümlerin birbirinden bağımsız, farklı birimden alınan ölçümlerin ise sabit değişkenliğe sahip olmasını gerektirir. Bağımsız çalışan korelasyon yapısının matematiksel ifadesi Eşitlik 3'teki gibidir.

$\mathrm{R}_{\mathrm{i}}(\mathrm{a})=\left(\begin{array}{cccc}1 & 0 & 0 & 0 \\ 0 & 1 & 0 & 0 \\ 0 & 0 & 1 & 0 \\ 0 & 0 & 0 & 1\end{array}\right)$

Değiştirilebilir (exchangeable) çalışan korelasyon yapısı ise aynı birimden alınan ölçümler arasındaki korelasyonların eşitliği üzerine kuruludur. Değiştirilebilir çalışan korelasyon yapısının matematiksel ifadesi Eşitlik 4'teki gibidir.

$\mathrm{R}_{\mathrm{i}}(\mathrm{a})=\left(\begin{array}{cccc}1 & \alpha & \alpha & \alpha \\ \alpha & 1 & \alpha & \alpha \\ \alpha & \alpha & 1 & \alpha \\ \alpha & \alpha & \alpha & 1\end{array}\right)$

Yapılandırılmamış (unstructured) çalışan korelasyon yapısı m(m-1)/2 kadar parametreye sahip olan ve daha çok kümedeki gözlemlerin küçük olduğu durumlarda ideal parametre tahminlerini gerçekleştirebilen bir korelasyon yapısıdır. Yapılandırılmamış çalışan korelasyon yapısının matematiksel ifadesi Eşitlik 5'teki gibidir.

$\mathrm{R}_{\mathrm{i}}(\alpha)=\left(\begin{array}{cccc}1 & \alpha_{12} & \alpha_{13} & \alpha_{14} \\ \alpha_{12} & 1 & \alpha_{23} & \alpha_{24} \\ \alpha_{13} & \alpha_{23} & 1 & \alpha_{34} \\ \alpha_{14} & \alpha_{24} & \alpha_{34} & 1\end{array}\right)$

Literatürde yaygın olarak kullanılan son çalışan korelasyon yapısı ise AR-1 (birinci dereceden otoregresif) çalışan korelasyon yapısıdır. Bu korelasyon yapısı gözlemler arasında eşit zaman aralığı bulunan veri setleri için en uygun korelasyon yapısı olarak kabul edilmektedir. AR-1 çalışan korelasyon yapısının matematiksel ifadesi Eşitlik 6'daki gibidir (Kılıç ve Çilingirtürk, 2012).

$\mathrm{R}_{\mathrm{i}}(\alpha)=\left(\begin{array}{cccc}1 & \alpha & \alpha^{2} & \alpha^{3} \\ \alpha & 1 & \alpha & \alpha^{2} \\ \alpha^{2} & \alpha & 1 & \alpha \\ \alpha^{3} & \alpha^{2} & \alpha & 1\end{array}\right)$

GTD ile gerçekleştirilen çalışmalarda genellikle araştırmacılar farklı çalışan korelasyon yapılarını denemekte ve en ideal olan çalışan korelasyon yapısına karar vermeye çalışmaktadır. Bu karar, çalışan korelasyon yapılarının yukarıda sıralanan özelliklerine göre de uyum iyiliği kriterlerine de başvurulabilmektedir. Burada en yaygın olarak kullanılan uyum iyiliği kriteri Bilgi Kriterleridir (Information Criteria: IC). Akaike Bilgi Kriteri' ne (AIC) dayanan temeli ile en sık kullanılan bilgi kriteri ise QIC (Quasilikelihood under the Independence model Criterion) olarak karşımıza çıkmaktadır. Bu kriter farklı çalışan korelasyon yapıları ile kurulmuş modellerin karşılaştırılması için kullanılmaktadır. AIC'te olduğu gibi QIC kriterinde de hesaplanan değerin minimum olduğu çalışan korelasyon yapısının kullanıldığı model en ideal model olarak belirlenir (Kılıç ve Çilingirtürk, 2012). 


\section{Analiz ve bulgular}

Çalışma kapsamında çalışma saatlerinin İGE değeri ve alt parametreleri ile ilişkisinin incelenmesi için kullanılan GTD yönteminin genel formülasyonu Eşitlik 7'deki gibidir.

$Y=B(0) \pm B(1) \pm \ldots \pm ß(n) \pm$ Zaman

Eşitlik 7'de görülebileceği üzere GTD, bağımsız değişken veya değişkenlerin tek bir bağımlı değişken üzerindeki etkisini incelemeye yönelik olarak gerçekleştirilmekte aynı zamanda zaman etkisi hesaplanmaktadır. Bu nedenle çalışmada hdi, sch, lexp ve gni değişkenlerinin bağımlı değişken ve wh ile zaman değişkenlerinin ise bağımsız değişken olduğu modeller kurulmuştur. Çalışan korelasyon yapısı olarak literatürde en çok kullanılan; Bağımsız, Değiştirilebilir, Yapılandırılmamış ve AR-1 çalışan korelasyon yapıları tercih edilmiştir. Her bir çalışan korelasyon yapısı için kurulan dört model sonucu toplamda 16 farklı model çıktısı elde edilmiş ve bu çıktılar QIC kriteri üzerinden karşılaştırılmıştır. Tablo 3 Değiştirilebilir Çalışan Korelasyon yapısına ilişkin analiz çıktılarını yansıtmaktadır.

Tablo 3. Değiştirilebilir Çalışan Korelasyon Yapısına İlişkin Analiz Çıktıları

\begin{tabular}{|c|c|c|c|c|c|c|}
\hline $\begin{array}{l}\text { Bağımlı } \\
\text { Değişken }\end{array}$ & $\begin{array}{l}\text { Bağımsız } \\
\text { Değişken }\end{array}$ & $\begin{array}{c}\text { Parametre } \\
\text { Tahmini }\end{array}$ & $\begin{array}{c}\text { Standart } \\
\text { Hata }\end{array}$ & $\begin{array}{c}\text { Wald } \\
\text { İstatistiği }\end{array}$ & Olasılık & QIC \\
\hline \multirow{3}{*}{ hdi } & Sabit & $9.29 \mathrm{e}-01$ & $6.42 \mathrm{e}-02$ & 209.02 & $<2 \mathrm{e}-16^{* * *}$ & \multirow{3}{*}{24.185} \\
\hline & Wh & $-2.94 \mathrm{e}-05$ & $3.87 \mathrm{e}-05$ & 0.58 & 0.45 & \\
\hline & Zaman & $3.22 \mathrm{e}-03$ & $3.21 \mathrm{e}-04$ & 100.93 & $<2 \mathrm{e}-16^{* * *}$ & \\
\hline \multirow{3}{*}{ sch } & Sabit & 15.38430 & 2.19721 & 49.02 & $2.5 \mathrm{e}-12 * * *$ & \multirow{3}{*}{384.26} \\
\hline & Wh & -0.00224 & 0.00130 & 2.98 & 0.084 . & \\
\hline & Zaman & 0.06739 & 0.01519 & 19.69 & $9.1 \mathrm{e}-06^{* * *}$ & \\
\hline \multirow{3}{*}{$\operatorname{lexp}$} & Sabit & 83.33514 & 2.54865 & 1069.14 & $<2 \mathrm{e}-16^{* * *}$ & \multirow{3}{*}{1699.8} \\
\hline & Wh & -0.00236 & 0.00152 & 2.42 & 0.12 & \\
\hline & Zaman & 0.18386 & 0.01659 & 122.79 & $<2 \mathrm{e}-16^{* * *}$ & \\
\hline \multirow{3}{*}{ gni } & Sabit & 42452.88 & 22586.28 & 3.53 & 0.06 . & \multirow{3}{*}{$3.54 \mathrm{e}+10$} \\
\hline & Wh & -4.81 & 13.21 & 0.13 & 0.72 & \\
\hline & Zaman & 512.66 & 125.55 & 16.67 & $4.4 \mathrm{e}-05^{* * *}$ & \\
\hline
\end{tabular}

Kaynak: Yazarlar tarafından üretilmiştir. Not: *\%1, **\%5, ***\%10

Tablo 3 'te görüldüğü üzere değiştirilebilir çalışan korelasyon yapısı ile gerçekleştirilen analizler sonucunda; $h d i$, sch ve lexp değişkenleri için sabit katsayı ve zaman değişkenleri istatistiksel açıdan anlamlı bulunmuş, gni değişkeni için yalnızca zaman değişkeninin katsayısı anlamlı kabul edilmiştir. Çalışmada kullanılan esas değişken olan wh ise hiçbir modelde anlamlı bulunmamıştır. Tablo 4 AR-1 Çalışan Korelasyon yapısına ilişkin analiz çıktılarını yansıtmaktadır.

Tablo 4. AR-1 Çalışan Korelasyon Yapısına İlişkin Analiz Çıktıları

\begin{tabular}{|c|c|c|c|c|c|c|}
\hline $\begin{array}{l}\text { Bağımlı } \\
\text { Değişken }\end{array}$ & $\begin{array}{l}\text { Bağımsız } \\
\text { Değişken }\end{array}$ & $\begin{array}{c}\text { Parametre } \\
\text { Tahmini }\end{array}$ & $\begin{array}{c}\text { Standart } \\
\text { Hata }\end{array}$ & $\begin{array}{c}\text { Wald } \\
\text { İstatistiği }\end{array}$ & Olasılık & QIC \\
\hline \multirow{3}{*}{ hdi } & Sabit & $9.48 \mathrm{e}-01$ & $3.39 \mathrm{e}-02$ & 782.7 & $<2 \mathrm{e}-16^{* * *}$ & \multirow{3}{*}{8.04} \\
\hline & wh & $-4.08 \mathrm{e}-05$ & $2.12 \mathrm{e}-05$ & 3.7 & 0.055 . & \\
\hline & Zaman & $3.14 \mathrm{e}-03$ & $2.64 \mathrm{e}-04$ & 142.1 & $<2 \mathrm{e}-16^{* * *}$ & \\
\hline \multirow{3}{*}{ sch } & Sabit & 15.068987 & 1.277853 & 139.06 & $<2 \mathrm{e}-16^{* * *}$ & \multirow{3}{*}{375.2} \\
\hline & wh & -0.002052 & 0.000789 & 6.77 & 0.0093 ** & \\
\hline & Zaman & 0.063546 & 0.012254 & 26.89 & $2.2 \mathrm{e}-07^{* * *}$ & \\
\hline \multirow{3}{*}{ lexp } & Sabit & 80.346774 & 0.853707 & 8857.67 & $<2 \mathrm{e}-16^{* * *}$ & \multirow{3}{*}{1772.66} \\
\hline & wh & -0.000641 & 0.000458 & 1.96 & 0.16 & \\
\hline & Zaman & 0.190597 & 0.015661 & 148.12 & $<2 \mathrm{e}-16^{* * *}$ & \\
\hline \multirow{3}{*}{ gni } & Sabit & 49840.23 & 8469.31 & 34.63 & $4.0 \mathrm{e}-09 * * *$ & \multirow{3}{*}{$3.27 \mathrm{e}+10$} \\
\hline & wh & -8.93 & 4.80 & 3.46 & 0.063 . & \\
\hline & Zaman & 503.28 & 101.27 & 24.70 & $6.7 \mathrm{e}-07^{* * *}$ & \\
\hline
\end{tabular}

Kaynak: Yazarlar tarafından üretilmiştir. Not: *\%1, **\%5, $* * * \% 10$ 
Tablo 4'te görüldüğgü üzere AR-1 çalışan korelasyon yapısı ile gerçekleştirilen analizler sonucunda; $h d i$, sch, lexp ve gni değişkenleri için sabit katsayı ve zaman değişkenleri istatistiksel açıdan anlamlı bulunmuş, wh değişkenine ilişkin katsayı ise yalnızca sch değişkeni ile kurulan modelde istatistiksel açıdan anlamlı bulunmuştur. Tablo 5 Yapılandırılmamış Çalışan Korelasyon yapısına ilişkin analiz çıktılarını göstermektedir.

Tablo 5. Yapılandırılmamış Çalışan Korelasyon Yapısına İlişkin Analiz Çıktıları

\begin{tabular}{|c|c|c|c|c|c|c|}
\hline $\begin{array}{c}\text { Bağımlı } \\
\text { Değişken }\end{array}$ & $\begin{array}{l}\text { Bağımsız } \\
\text { Değişken }\end{array}$ & $\begin{array}{c}\text { Parametre } \\
\text { Tahmini }\end{array}$ & $\begin{array}{c}\text { Standart } \\
\text { Hata }\end{array}$ & $\begin{array}{c}\text { Wald } \\
\text { İstatistiği }\end{array}$ & Olasılık & QIC \\
\hline \multirow{3}{*}{ hdi } & Sabit & $1.09 \mathrm{e}+00$ & $6.92 \mathrm{e}-02$ & 250.18 & $<2 \mathrm{e}-16^{* * *}$ & \multirow{3}{*}{9.069} \\
\hline & wh & $-1.27 e-04$ & $4.26 \mathrm{e}-05$ & 8.93 & $0.0028^{* *}$ & \\
\hline & Zaman & $2.99 \mathrm{e}-03$ & $3.57 \mathrm{e}-04$ & 70.16 & $<2 \mathrm{e}-16^{* * *}$ & \\
\hline \multirow{3}{*}{ sch } & Sabit & 16.28760 & 1.79827 & 82.0 & $<2 \mathrm{e}-16^{* * *}$ & \multirow{3}{*}{367.86} \\
\hline & wh & -0.00277 & 0.00109 & 6.5 & 0.011 * & \\
\hline & Zaman & 0.06397 & 0.01499 & 18.2 & $2 \mathrm{e}-05 * * *$ & \\
\hline \multirow{3}{*}{ lexp } & Sabit & 112.40322 & 7.78430 & 208.51 & $<2 \mathrm{e}-16^{* \star *}$ & \multirow{3}{*}{3926.58} \\
\hline & wh & -0.01933 & 0.00465 & 17.25 & $3.3 e-05 * * *$ & \\
\hline & Zaman & 0.08244 & 0.02796 & 8.69 & $0.0032 * *$ & \\
\hline \multirow{3}{*}{ gni } & Sabit & 90319.5 & 91272.7 & 0.98 & 0.322 & \multirow{3}{*}{$2.28 \mathrm{e}+10$} \\
\hline & wh & -33.2 & 53.9 & 0.38 & 0.538 & \\
\hline & Zaman & 526.8 & 216.3 & 5.93 & 0.015 * & \\
\hline
\end{tabular}

Kaynak: Yazarlar tarafından üretilmiştir. Not: *\%1, **\%5, $\%$ ***\%10

Tablo 5'te görüldüğü üzere yapılandırılmamış çalışan korelasyon yapısı ile gerçekleştirilen analizler sonucunda; $h d i$, sch ve lexp değişkenleri için sabit katsayı ve zaman değişkenleri istatistiksel açıdan anlamlı bulunmuş, gni değişkeni için yalnızca zaman değişkeninin katsayısı anlamlı kabul edilmiştir. Bir diğer değişken olan $w h$ ise gni ile kurulan model dışındaki tüm modellerde anlamlı kabul edilmiştir. Tablo 6 Bağımsız Çalışan Korelasyon yapısına ilişkin analiz çıktılarını yansıtmaktadır.

Tablo 6. Bağımsız Çalışan Korelasyon Yapısına İlişkin Analiz Çıktıları

\begin{tabular}{|c|c|c|c|c|c|c|}
\hline $\begin{array}{l}\text { Bağımlı } \\
\text { Değişken }\end{array}$ & $\begin{array}{l}\text { Bağımsız } \\
\text { Değişken }\end{array}$ & $\begin{array}{c}\text { Parametre } \\
\text { Tahmini }\end{array}$ & $\begin{array}{c}\text { Standart } \\
\text { Hata }\end{array}$ & $\begin{array}{c}\text { Wald } \\
\text { İstatistiği }\end{array}$ & Olasılık & QIC \\
\hline \multirow{3}{*}{ hdi } & Sabit & $1.09 \mathrm{e}+00$ & $6.92 \mathrm{e}-02$ & 250.18 & $<2 \mathrm{e}-16^{* * *}$ & \multirow{3}{*}{43.740} \\
\hline & wh & $-1.27 \mathrm{e}-04$ & $4.26 \mathrm{e}-05$ & 8.93 & 0.0028 ** & \\
\hline & Zaman & $2.99 \mathrm{e}-03$ & $3.57 \mathrm{e}-04$ & 70.16 & $<2 \mathrm{e}-16^{* * *}$ & \\
\hline \multirow{3}{*}{ sch } & Sabit & 16.50300 & 1.81528 & 82.65 & $<2 \mathrm{e}-16^{* * *}$ & \multirow{3}{*}{395.0} \\
\hline & wh & -0.00290 & 0.00111 & 6.82 & $0.009^{* *}$ & \\
\hline & Zaman & 0.06505 & 0.01352 & 23.15 & $1.5 \mathrm{e}-06^{* * *}$ & \\
\hline \multirow{3}{*}{ lexp } & Sabit & 86.25483 & 3.15949 & 745.30 & $<2 \mathrm{e}-16^{* * *}$ & \multirow{3}{*}{1678.4} \\
\hline & wh & -0.00408 & 0.00193 & 4.44 & 0.035 * & \\
\hline & Zaman & 0.17775 & 0.01790 & 98.61 & $<2 \mathrm{e}-16^{* * *}$ & \\
\hline \multirow{3}{*}{ gni } & Sabit & 105475.39 & 12798.36 & 67.9 & $2.2 \mathrm{e}-16^{* * *}$ & \multirow{3}{*}{$2.21 \mathrm{e}+10$} \\
\hline & wh & -41.79 & 7.36 & 32.2 & $1.4 \mathrm{e}-08^{* * *}$ & \\
\hline & Zaman & 380.93 & 109.33 & 12.1 & $0.00049^{* * *}$ & \\
\hline
\end{tabular}

Kaynak: Yazarlar tarafından üretilmiştir. Not: *\%1, **\%5, ***\%10

Bağımsız çalışan korelasyon yapısı ile gerçekleştirilen analizlerde ise bütün modellerde tüm değişkenlere ilişkin katsayı değerleri istatistiksel olarak anlamlı bulunmuştur.

Bütün çalışan korelasyon yapıları ile gerçekleştirilen analiz çıktılarının sunulmasından sonra her bir bağımlı değişken için hangi çalışan korelasyon yapısı ile gerçekleştirilen analiz sonucunun istatistiksel olarak daha anlamlı ve doğru kabul edileceğinin belirlenmesi gerekmektedir. Bunun için QIC kriteri kullanılacaktır. Her bir analiz çıktısına ilişkin QIC değeri Tablo 7'de sunulmuştur. 
Tablo 7. Analiz Çıktılarının QIC Değerleri

\begin{tabular}{|c|c|c|c|c|}
\hline \multirow{2}{*}{ Bağımlı Değişken } & \multicolumn{4}{|c|}{ Çalışan Korelasyon Yapısı } \\
\cline { 2 - 5 } & Değiştirilebilir & AR-1 & Yapılandırılmamış & Bağımsız \\
\hline hdi & 24.185 & $\mathbf{8 . 0 4}$ & 9.069 & 43.740 \\
\hline sch & 384.26 & 375.2 & 367.86 & 395.0 \\
\hline lexp & 1699.8 & 1772.66 & 3926.58 & $\mathbf{1 6 7 8 . 4}$ \\
\hline gni & $3.54 \mathrm{e}+10$ & $3.27 \mathrm{e}+10$ & $2.28 \mathrm{e}+10$ & $\mathbf{2 . 2 1 e + 1 0}$ \\
\hline
\end{tabular}

Kaynak: Yazarlar tarafından üretilmiştir.

Tablo 7'de görülebileceği üzere QIC değerlerinin en düşük değerleri; $h d i$ değişkeni ile kurulan model için AR-1 çalışan korelasyon yapısında, sch değişkeni ile kurulan model için yapılandırılmamış çalışan korelasyon yapısında ve lexp ile gni değişkenleri ile kurulan modeller için ise bağımsız çalışan korelasyon yapısında elde edilmektedir. Tablo 8 ideal kabul edilen modellere ilişkin özet çıktıları sunmaktadir.

Tablo 8. İdeal Modellerin Çıktıları

\begin{tabular}{|c|c|c|c|c|c|c|c|}
\hline $\begin{array}{c}\text { Bağımlı } \\
\text { Değişken }\end{array}$ & $\begin{array}{l}\text { Bağımsız } \\
\text { Değişken }\end{array}$ & $\begin{array}{c}\text { Parametre } \\
\text { Tahmini }\end{array}$ & $\begin{array}{l}\text { Standart } \\
\text { Hata }\end{array}$ & $\begin{array}{c}\text { Wald } \\
\text { İstatistiği }\end{array}$ & Olasılık & QIC & $\begin{array}{c}\text { Korelasyon } \\
\text { Yapis1 }\end{array}$ \\
\hline \multirow{3}{*}{ hdi } & Sabit & $9.48 \mathrm{e}-01$ & $3.39 \mathrm{e}-02$ & 782.7 & $<2 \mathrm{e}-16^{* * *}$ & \multirow{3}{*}{8.04} & \multirow{3}{*}{ AR-1 } \\
\hline & wh & $-4.08 e-05$ & $2.12 \mathrm{e}-05$ & 3.7 & 0.055 . & & \\
\hline & Zaman & $3.14 \mathrm{e}-03$ & $2.64 \mathrm{e}-04$ & 142.1 & $<2 \mathrm{e}-16^{* * *}$ & & \\
\hline \multirow{3}{*}{ sch } & Sabit & 16.28760 & 1.79827 & 82.0 & $<2 \mathrm{e}-16^{* * *}$ & \multirow{3}{*}{367.86} & \multirow{3}{*}{ Yapılandırılmamış } \\
\hline & wh & -0.00277 & 0.00109 & 6.5 & 0.011 * & & \\
\hline & Zaman & 0.06397 & 0.01499 & 18.2 & $2 \mathrm{e}-05^{* * *}$ & & \\
\hline \multirow{3}{*}{ lexp } & Sabit & 86.25483 & 3.15949 & 745.30 & $<2 \mathrm{e}-16^{* * *}$ & \multirow{3}{*}{1678.4} & \multirow{3}{*}{ Bağımsız } \\
\hline & wh & -0.00408 & 0.00193 & 4.44 & 0.035 * & & \\
\hline & Zaman & 0.17775 & 0.01790 & 98.61 & $<2 \mathrm{e}-16^{* * *}$ & & \\
\hline \multirow{3}{*}{ gni } & Sabit & 105475.39 & 12798.36 & 67.9 & $2.2 \mathrm{e}-16^{* * *}$ & \multirow{3}{*}{$2.21 \mathrm{e}+10$} & \multirow{3}{*}{ Bağımsız } \\
\hline & wh & -41.79 & 7.36 & 32.2 & $1.4 \mathrm{e}-08$ *** & & \\
\hline & Zaman & 380.93 & 109.33 & 12.1 & $0.00049 * * *$ & & \\
\hline
\end{tabular}

Kaynak: Yazarlar tarafından üretilmiştir. Not: *\%1, **\%5, ***\%10

Tablo 8' de görülebileceği üzere $h d i$ değişkeni için; sabit katsayı ortalama 9.48e-01 olarak hesaplanmış ve zaman değişkenindeki bir birimlik artışn hdi üzerinde ortalama 3.14e-03 birim değişim oluşturacağını ortaya konmuştur. Burada wh değişkeni ile hdi değişkeni arasında istatistiksel olarak anlamlı bir ilişki olmadığı görülmüştür.

Bir diğer değişken olarak sch değişkeni için; sabit katsayı ortalama 16.28670 olarak hesaplanmış ve zaman değişkenindeki bir birimlik artışı sch değerlerinde ortalama 0.06397 birimlik değişim meydana getirdiği görülmüştür. Burada wh değişkeni ile sch değişkeni arasında istatistiksel olarak anlamlı bir ilişki tespit edilmiş ve çalışma saatlerindeki bir birimlik artışın ortalama eğitim yılı üzerinde ortalama $(-0.00277)$ birim etki yarattığı belirlenmiştir.

Çalışma saatleri ile ilişkisi bakımından incelenen bir diğer değişken ise lexp değişkenidir. Analiz sonuçlarına göre lexp değişkeni için sabit katsayı ortalama 86.25483 olarak hesaplanmış ve zaman değişkenindeki bir birimlik artış sonucunda lexp değerlerinde ortalama 0.17775 birim değişme gözlendiği belirlenmiştir. Burada wh değişkeni ile lexp değişkeni arasında istatistiksel olarak anlamlı bir ilişki tespit edilmiş ve çalışma saatlerindeki bir birimlik artışın beklenen yaşam süresinde ortalama (0.00408) birim değişime yol açtı̆̆ ortaya konmuştur.

Çalışmada incelenen son değişken ise gni olmuştur. Tablo 8 'de görülebileceği üzere gni değişkeni için; sabit katsayı ortalama 105475,39 olarak hesaplanmış ve zaman değişkenindeki bir birimlik artışın gni değerinde ortalama 380.93 birim değişim meydana getireceği belirlenmiştir. Kişi başına düşen milli gelirin çalışma saatleri ile ilişkisi ise anlamlı olarak tespit edilmiştir. Buna göre çalışma saatlerindeki bir birimlik artış kişi başına düşen milli gelirde ortalama (-41.79) birimlik bir değişim yaratmaktadır. 


\section{Sonuç ve değerlendirme}

Çalışma kapsamında 35 OECD ülkesine dair veriler ile çalışma saatleri ve İnsanî Gelişmişlik Endeksi arasındaki ilişkinin belirlenmesi hedeflenmiştir. Bu kapsamda yıllık ortalama çalışma saati ile İGE değeri, ortalama eğitim yıll, ortalama yaşam süresi ve kişi başına milli gelir değişkenleri arasındaki ilişkiye dair GTD uygulanmış ve sonuçları sunulmuştur. Çalışma kapsamında gerçekleştirilen analizler çalışma saatlerinin İGE değeri ile ilişkili olduğunu ortaya koymaktadır. Nitekim çalışma saatlerindeki bir birimlik artışın İGE parametreleri üzerinde ortalama olarak; ortalama eğitim yılında (-0.00277) birimlik, beklenen yaşam süresinde $(-0.00408)$ birimlik ve kişi başına düşen milli gelirde ise (-41.79) birimlik bir değişim yarattığı belirlenmiştir.

Gerçekleştirilen analiz sonuçlarına göre çalışma saatleri ile İnsanî Gelişmişlik Endeks parametreleri arasında ters yönlü bir ilişki olduğu görülmüştür. Bu durum haftada 5-6 gün ve günde 8-10 saatlik çalışma sistemini tartışmalı hale getirmektedir. Nitekim insanî gelişme, insan ve toplum refahı açısından bakıldığında mutlak bir hedeftir. Çalışmanın sonuçları ise uzun çalışma saatlerinin insanî gelişmeyi olumsuz etkilediğini ortaya koymaktadır. Tam da burada bugün özellikle Finlandiya başta olmak üzere çeşitli Avrupa ülkelerinde süren çalışma gün ve saatlerinin azaltılması ile ilgili tartışmaların önemi ortaya çıkmaktadır.

Bu sonuçlar, çalışma aktivitesinin tamamen ortadan kaldırılması halinde optimum insanî gelişmişlik seviyesine ulaşılacağı şeklinde yorumlanmamalıdır. Burada esas olan husus bu denli açık bir ilişkinin yarattığı sorunların önüne geçmek adına, insan odaklı yeni bir çalışma ve yaşam anlayışının gerekliliğidir. Bu gereklilik, özelde iş yaşamı ve genelde toplumsal yaşamda verimlilik odaklı yeni bir paradigmanın geliştirilmesine yönelik ihtiyaca karşılık gelmektedir. Çalışmanın sonuçlarına ek olarak günümüzdeki teknolojik imkanlar ve bu doğrultuda gelişen dijital topluma dönüşüm hareketliliği düşünüldüğünde bu paradigmanın önemi ve değeri anlaşılabilmektedir.

\section{Hakem Değerlendirmesi / Peer-review:}

Dış bağımsız

Externally peer-reviewed

\section{Çıkar Çatışması / Conflict of interests:}

Yazar(lar) çıkar çatışması bildirmemiştir.

The author(s) has (have) no conflict of interest to declare.

\section{Finansal Destek/ Grant Support:}

Yazar bu çalışma için finansal destek almadığını beyan etmiştir.

The author declared that this study has received no financial support.

\section{Kaynakça / References}

Akhtar, S., Kashif, A., Arif, A., \& Khan, M. A. (2012). Impact of long working hours on family wellbeing of corporate family. World Applied Sciences Journa, 16(9), 1302-1307.ta

Collowet, M., \& Sauermann, J. (2019). Working hours and productivity. Maastricht: Research Centre for Education and the Labour Market.

Çalışkan, N. (2013). Genelleştirilmiş tahmin denklemleri ve regresyon ile başarı kestirimlerinin karşılaştırılması. Yayınlanmamış Doktora Tezi. Ankara: Hacettepe Üniversitesi Eğitim Bilimleri Enstitüsü Eğitim Bilimleri Anabilim Dalı Eğitimde Ölçme ve Değerlendirme Bilim Dalı .

Fursman, L. (2009). Parent's long work hours and the impact on family life. Social Policy Journal of New Zealand(35), 55-67. 
Halekoh, U., Hojsgaard, S., \& Yan, J. (2006). The R package geepack for Generalized Estimate Equations. Journal of Statistical Software, 15(2), 1-11.

Jorgenson, A. K., Fitzgerald, J. B., Thombs, R. P., Hill, T. D., Givens, J. E., Clark, B., . . Ore, P. (2020). The multiplicative impacts of working hours and fine particulate matter concentration on life expectancy: A longitudinal analysis of US States. Environmental Research, 191. doi:https:// doi.org/10.1016/j.envres.2020.110117

Kılıç, S., \& Çilingirtürk, A. M. (2012). Genelleştirilmiş tahmin denklemlerinde entropye dayalı korelasyon matrisi yaklaşımı: Türk bankacılık sektörü uygulaması. Anadolu Üniversitesi Sosyal Bilimler Dergisi, 13(2), 91-100.

Klafke, R. (2017). The relationship between the human development index, free time and weekly hours worked by the Brazilian population. Rev. Guillermo de Ockham, 15(2), 95-101.

Meydan, M. C., \& Sarı, V. İ. (2018). İnsanî Gelişme Endeksi ve Alt Endekslerinin Türkiye'deki İller İçin Ölçülmesi ve Analizi. idealkent, 9(24), 387-429. doi:10.31198/idealkent.450118

OECD. (2019). Hours worked. 01 03, 2021 tarihinde https://data.oecd.org/emp/hours-worked.htm adresinden alınd 1

Rannis, G., Stewart, F., \& Samman, E. (2006). Human development: beyon the Human Development Index. Journal of Human Development, 7(3), 323-358. doi:https:/ / doi.org/10.1080/14649880600815917

Sagar, A. D., \& Najam, A. (1998). The Human Development Index: a critical review. Ecological Economics, 25(3), 249-264. doi:https://doi.org/10.1016/S0921-8009(97)00168-7

Schein, A., \& Haruvi, N. (2017). The Relationship between the Average Workweek Length and Per Capita Gross Domestic Product (GDP). International Studies of Management \& Organization, 47, 311323. doi:https://doi.org/10.1080/00208825.2017.1382268

Şeker, G., Tilbe, A., Ökmen, M., Yazgan Hepgül, P., Eroğlu, D., \& Sirkeci, İ. (2015). Londra'da çalışan Türkiyeli göçmenlerin çalışma süreleri ve sosyal ilişkileri. Turkish Migration Conference 2015 Selected Proceedings. Londra: Transnational Press.

T.C. Kalkınma Bakanlığı Sosyal Sektörler ve Koordinasypn Genel Müdürlüğü. (2011). Türkiye'nin İnsan̂̂ Gelişme Endeki ve Endeks Sıralamasının Analizi. Ankara: T.C. Kalkınma Bakanlığı. 12 03, 2020 tarihinde https://sbb.gov.tr/wpcontent/uploads/2018/11/Turkiyenin_Insani_Gelisme_EndeksiveEndeksSiralamasininAnalizi.pd $\mathrm{f}$ adresinden alınd 1

UNDP. (2018). Human Development Indices and Indicators: 2018 Statistical Update. doi:10.17719/jisr.2019.3166

UNDP. (2019). HUMAN DEVELOPMENT REPORT 2019: Technical notes.

UNDP. (2020). UNDP Human Development Report. hdr.undp.org: http://hdr.undp.org/en/indicators/137506 adresinden alınd1

UNDP. GNI Per Capita. 01 03, 2021 tarihinde http://hdr.undp.org/en/indicators/141706 adresinden alındı

UNDP. Human Development Index (HDI). 01 03, 2021 tarihinde http://hdr.undp.org/en/indicators/137506 adresinden alındı

UNDP. Life expectancy at birth (years). 01 03, 2021 tarihinde http://hdr.undp.org/en/indicators/69206 adresinden alındı

UNDP. Mean years of schooling (years). 01 03, 2021 tarihinde http://hdr.undp.org/en/indicators/103006 adresinden alındı

United Nations Development Programme. (2020, 12 05). United Nations Development Programme. United Nations Development Programme: http://hdr.undp.org/en/humandev adresinden alındı

Usta, D., \& Çilingirtürk, A. M. (2018). Bitişme Analizi faydalarının Genelleştirilmiş Tahmin Denklemleri ile belirenmesi. UIIIID-IJEAS, 11-22. doi:10.18092/ulikidince.354777

Wong, K., Chan, A. H., \& Ngan, S. C. (2012). The effect of long working hours and overtime on occupational health: A meta-analysis of evidence from 1998 to 2018. International Journal of Environmental Research and Public Health, 16(12). doi:10.3390/ijerph16122102 
Yiğit, T. (2020). Sosyal hizmetin mesleki kimliği: her koşulda insanlığın yanında olan meslek. Türkiye Sosyal Hizmet Araştırmaları Dergisi, 4(2), 9-19.

Yonar, H., \& İyit, N. (2018). Modeling the causality relationships between Gdp/Gni and electricity consumption according to income levels of countries by Generalized Estimating Equations. Selçuk Üniversitesi Sosyal Bilimler Enstitüsü Dergisi(39), 191-200. 